\title{
Notch-Fatigue Properties of Advanced TRIP-Aided Bainitic Ferrite Steels
}

\author{
NOBUO YOSHIKAWA ${ }^{*}$, JUNYA KOBAYASHI ${ }^{*}$ and KOH-ICHI SUGIMOTO**
}

* Graduate School, Shinshu University, 4-17-1, Wakasato, Nagano, 380-8553 Japan

E-mail: yoshikawa@sugimotolab.shinshu-u.ac.jp, koba@sugimotolab.shinshu-u.ac.jp

** Dept. of Mechanical Systems Engineering, Shinshu University, 4-17-1, Wakasato, Nagano, 380-8553 Japan

E-mail: sugimot@shinshu-u.ac.jp

To develop a transformation-induced plasticity (TRIP)-aided bainitic ferrite steel (TBF steel) with high hardenability for a common rail of the next generation diesel engine, $0.2 \% \mathrm{C}-1.5 \% \mathrm{Si}-1.5 \% \mathrm{Mn}-0.05 \% \mathrm{Nb}$ TBF steels with different content of $\mathrm{Cr}$, Mo and Ni were produced. And, notch-fatigue strength of the TBF steels was investigated and was related to the microstructural and retained austenite characteristics. If $\mathrm{Cr}, \mathrm{Mo}$ and/or $\mathrm{Ni}$ were added to the base steel, the steels achieved extremely higher notch-fatigue limits and lower notch-sensitivity than base TBF steel and the conventional structural steels. This was mainly associated with (i) carbide-free and fine bainitic ferrite lath structure matrix without pro-eutectoid ferrite, (ii) a large amount of fine metastable retained austenite and (iii) blocky martensite phase including retained austenite, which may suppress a fatigue crack initiation and propagation.

Key words: fatigue, notch sensitivity, microstructure, retained austenite, ultra high-strength steel, TRIP-aided steel 


\section{INTRODUCTION}

Advanced C-Si-Mn high-strength transformation-induced plasticity (TRIP)-aided steel with bainitic ferrite structure matrix (TRIP-aided bainitic ferrite steel; TBF steel) ${ }^{[1-4]}$ possesses a good combination of tensile strength and stretch-flangeability. So, commercial TBF steels with tensile strength of 980-1180 $\mathrm{MPa}$ are applied to some automotive members in Japan. The TBF steel also exhibits high fatigue limit ${ }^{[5]}$ and low notch-sensitivity for fatigue, ${ }^{[6]}$ as well as an excellent impact toughness ${ }^{[7]}$ and high delayed fracture strength. ${ }^{[8]}$ So, some applications to diesel engine common rail system which needs high inner pressure above $300 \mathrm{MPa}$ can be expected, if the TBF steel has a high hardenability and high notch-fatigue limit. However, there is not any research on notch-fatigue properties of the TBF steel with high hardenability.

In the present study, $\mathrm{Cr}$, Mo and/or $\mathrm{Ni}$ were added into a $0.2 \% \mathrm{C}-1.5 \% \mathrm{Si}-1.5 \% \mathrm{Mn}-0.05 \% \mathrm{Nb}$ TBF base steel. And, notch-fatigue properties of these TBF steels were investigated and were compared with those of commercial Cr-Mo bearing structural steels (SCM420, SCM435 and SCM440 steels). In addition, the notch-fatigue limit and notch-sensitivity were related to metallurgical factors such as microstructure and retained austenite characteristics. 
In the present work, five kinds of steel bars A through $\mathrm{E}$ with different $\mathrm{Cr}$, Mo and Ni contents were prepared by vacuum melting, followed by hot forging and hot rolling. The chemical composition of steels A-E is listed in Table I, where $\mathrm{Nb}$ of $0.05 \%$ is added to refine the prior austenitic grain. For comparison, commercial SCM420 (F) and SCM435 (G) steels and vacuum melted SCM440 (H) steel were used.

After smooth and notched specimens for tension and fatigue tests (Figure 1) were machined from the steel bars, heat treatment illustrated by Figure 2 was conducted in salt baths for steels A-E. For steels F, G and H, quenching in oil after austenitizing at $900^{\circ} \mathrm{C}$ and then tempering at $200-600^{\circ} \mathrm{C}$ for 3600 s were carried out.

Hardenability of the steels was defined by a product of multiplying factors or the Grossman pearlitic hardenability factor $\left(\Pi f_{i}\right)^{[9,10]}$ computed from the following equation.

$$
\begin{aligned}
D_{\mathrm{I}} / D_{\mathrm{I}}^{*}=\Pi f_{\mathrm{i}}= & (1+0.64 \% S i) \times(1+4.10 \% M n) \times(1+2.83 \% P) \times(1-0.62 \% S) \times(1+2.33 \% C r) \\
& \mathrm{x}(1+0.52 \% \mathrm{Ni}) \times(1+3.14 \% \mathrm{Mo}) \times(1+0.27 \% \mathrm{Cu}) \times(1+1.5(0.9-\% \mathrm{C}))
\end{aligned}
$$

where $D_{\mathrm{I}}$ and $D_{\mathrm{I}}^{*}$ are a critical diameter and ideal critical diameter for hardenability, respectively. And, $\% S i, \% M n, \% P, \% S, \% C r, \% N i, \% M o, \% C u$ and $\% C$ represent 
added content (mass\%) of individual alloying elements. The last term of right side in Eq. [1] is available only for boron bearing steel.

Retained austenite characteristics of the steels A-E were investigated by X-ray diffractometry. The specimens were electro-polished after grinding with Emery paper (\#2000). Volume fraction of retained austenite $\left(f_{\gamma}\right.$, vol\%) was quantified from integrated intensity of (200) $\alpha,(211) \alpha,(200) \gamma,(220) \gamma$ and (311) $\gamma$ peaks by X-ray diffractometry using Mo-K $\alpha$ radiation. ${ }^{[11]}$ The carbon concentration $\left(C_{\gamma}\right.$, mass $\left.\%\right)$ was estimated from the following empirical equation. In this case, lattice constant $\left(a_{\gamma}, \mathrm{x} 0.1 \mathrm{~nm}\right)$ was measured from $(200) \gamma,(220) \gamma$ and $(311) \gamma$ peaks of $\mathrm{Cu}-\mathrm{K} \alpha$ radiation. ${ }^{[12]}$

$$
\begin{aligned}
a_{\gamma}=3.5780+0.0330 \% C_{\gamma}+0.00095 \% \mathrm{Mn}_{\gamma}-0.0002 \% \mathrm{Ni}_{\gamma}+0.0006 \% \mathrm{Cr}_{\gamma}+0.0220 \% N_{\gamma} \\
+0.0056 \% \mathrm{Al}_{\gamma}+0.0031 \% \mathrm{Mo}_{\gamma}+0.0051 \% N b_{\gamma}
\end{aligned}
$$

where $\% M n_{\gamma}, \% N i_{\gamma}, \% C r_{\gamma}, \% N_{\gamma}, \% A l_{\gamma}, \% C o_{\gamma}, \% C u_{\gamma}, \% M o_{\gamma}, \% N b_{\gamma}, \% T i_{\gamma}, \% V_{\gamma}$ and $\% W_{\gamma}$ represent concentration of individual elements (mass $\%$ ) in retained austenite, respectively. As an approximation, added contents of the above alloying elements were substituted for these concentrations in this study.

Microstructure of the steels was observed by field emission - scanning electron 
microscope (FE-SEM) with electron backscatter diffraction pattern (EBSP) equipment and transmission electron microscope (TEM). Specimens for the FE-SEM EBSP analysis were ground by silicon colloidal after alumina grinding. Vickers hardness test was carried out on a micro Vickers hardness tester (load: $0.98 \mathrm{~N})$ at $25^{\circ} \mathrm{C}$.

Surface of all specimens for tension and fatigue tests was ground by \#600 Emery paper before testing. Tension tests were conducted using a hard type of testing machine at $25^{\circ} \mathrm{C}$ and at a cross head speed of $1 \mathrm{~mm} / \mathrm{min}$ or a strain rate of $6.7 \times 10^{-4} / \mathrm{s}$. Fatigue tests were carried out on a multi-type fatigue testing machine (Takes-Group Ltd., PMF4-10) at $25^{\circ} \mathrm{C}$ and at a stress ratio of $\mathrm{R}=0.1$ with a sinusoidal wave of $80 \mathrm{~Hz}$ (Figure 3). Fatigue limit was defined by maximum stress amplitude $\left(\sigma_{R}\right)$ without failure up to $10^{7}$ cycles.

\section{RESULTS}

\section{A. Microstructure and Retained Austenite Characteristics}

Figure 4 shows phase maps, inverse pole figure map and image quality distribution Fig. 4 maps of steels A and D. Figure 5 shows SEM images of steels A through E and typical Fig. 5 TEM image. Microstructure of these steels principally consists of bainitic ferrite lath structure matrix and blocky second phase. In steel A, the bainitic ferrite is wide and 
granular and coarse retained austenite phases are mainly located along the bainitic ferrite lath boundaries (Figure 4(a)-(d)). In addition, there is a large amount of pro-eutectoid ferrite (Fig. 5(a)). In this case, prior austenitic grain boundary is indistinct.

Bainitic ferrite lath structure matrix in steel D becomes uniform and fine, compared to steel A. It is noteworthy that volume fraction of blocky second phase (yellowish green phase in Figure 4(g)) considerably increases. It seems that many blocky second phases characterized by low image quality index exist on prior austenitic grain boundary and packet boundary. Also, most of the retained austenite phases which exist in the blocky second phase or on the bainitic ferrite lath boundaries have lower image quality index than those of steel A (Figure 4(d) and (h)). It is noteworthy that low image quality index indicates higher dislocation density. ${ }^{[13]}$ From Figure 5(a)-(e), volume fraction of pro-eutectoid ferrite decreases drastically by $\mathrm{Cr}$ addition of $0.5 \%$. In contrast, volume fraction of blocky island increases with increasing content of $\mathrm{Cr}$, Mo and/or Ni.

From TEM examination (Figure 5(f)), the above mentioned blocky second phase is found to be narrow lath-martensite structure without any twin. Although retained austenite morphology in the second phase is indistinct, it seems that retained austenite observed as dotted phase in second phase (Figures $4(\mathrm{~g})$ and $4(\mathrm{~h})$ ) is located along the narrow martensite lath boundary. These results suggest that the blocky second phase is 
similar to traditional M-A constituent. It is important that the steels A-E do not contain any cementite in the bainitic ferrite lath structure, differing from the conventional structural steels such as SCM steels, as previously reported. ${ }^{[1,4]}$

Figure 6(a) shows the variations in an initial volume fraction and carbon Fig. 6 concentration of retained austenite as a function of hardenability factor in steels A-E. It is found that the carbon concentration decreases with increasing hardenability. On the contrary, the volume fraction increases with hardenability except for steel E, with a considerable increase in volume fractions of second phase. Kobayashi et al. ${ }^{[14]}$ have reported that additions of $\mathrm{Cr}$ and Mo increase the volume fractions of retained austenite and second phase by delaying carbon partitioning into austenite. On the other hand, Ni addition considerably decreases the carbon concentration of retained austenite and increases the second phase fraction by lowering $T_{0}$ temperature where austenite and ferrite of the same chemical composition have identical free energies, as well as by delaying carbon concentration.

According to previous reports, ${ }^{[2,3]}$ retained austenite stability against the strain-induced transformation for TRIP-aided steel can be evaluated by "strain-induced transformation factor; $k$ " defined by the following equation, rather than the carbon concentration, if retained austenite morphology considerably changes. 
where $f_{\gamma}$ is volume fraction of retained austenite after strained by strain $\varepsilon$ and $f_{\gamma 0}$ is an initial volume fraction of retained austenite. Figure 6(b) shows the $k$ values of steels A-E. The $k$ values increase somewhat with increasing hardenability except for steel A, which corresponds to the hardenability dependence of carbon concentration of retained austenite (Figure 6(a)). According to Sugimoto et al., ${ }^{[2,3,14]} k$ values between 1 and 5 means to have nearly the same stability and to be stable enough. In steel A, relatively low retained austenite stability despite high carbon concentration is caused by isolated morphology, differing from morphology surrounded by narrow martensite in steels B-E.

\section{B. Notch-Tensile Strength}

Table II shows Vickers hardness and tensile properties of steels A-H. Vickers hardness of the steels A-E are between HV242 and HV430 and increases with increasing hardenability. The yield stresses or $0.2 \%$ offset proof stresses are almost constant except for steel A. However, the strain hardening rate increases with increasing hardenability of the steels, especially at an early stage. Resultantly, the tensile strength 
increases with increasing hardenability. Steels A-D possess larger total and uniform elongations than steels F-H.

Figure 7 shows notch-tensile properties of steels A-E. The notch-tensile strength Fig. 7 increases with increasing hardenability in the same way as tensile strength. Steels B-E exhibit higher notch-strength ratio than steel A, although the notch-strength ratios are lower than those of steels F-H (see Table II).

C. Notch-Fatigue Limits and Notch-Sensitivity for Fatigue

Figure 8 shows S-N curves of steels A-E. Figure 9 shows fatigue limits of smooth Fig. 8 and notched specimens and "notch-sensitivity factor $q$ " ${ }^{[15]}$ defined by the following equation.

$$
q=\left(K_{\mathrm{f}}-1\right) /\left(K_{\mathrm{t}}-1\right)
$$

where $K_{\mathrm{f}}$ and $K_{\mathrm{t}}$ are fatigue-notch factor $\left(=F L / F L_{\mathrm{N}}\right)$ and stress concentration factor $(1.7$ in this study), respectively.

Both fatigue limits of smooth and notched specimens increase with increasing hardenability, although hardenability dependence of fatigue limit for smooth specimens 
is smaller than that for notched specimens (Figure 9(a)). The resultant notch-sensitivity apparently reduces with increasing hardenability in steels B-E (Figure 9(b)). Note that maximum stress $\left(\sigma_{\max }(\mathrm{FL})=F L / 0.9\right.$, Figure 3$)$ corresponding to fatigue limits for smooth specimens is higher than yield stress in steels A-E (Table II).

The fatigue limits of steels A-E hardly depended on the yield stress, differing from the conventional structural steels such as steels F-H. So, the smooth and notch-fatigue limits are plotted for Vickers hardness from a viewpoint of engineering convenience (Figure 10(a)). The notch-fatigue limits of steels C-E exhibit a linear relation to Vickers hardness, although fatigue limits for the smooth specimens are off from linear relation in a range above HV300. Resultantly, notch-sensitivity of the steels C-E decreases with an increase in Vickers hardness (Figure 10(b)), differing from that of steels F-H (SCM steels).

Figure 11 shows typical SEM image of fatigue crack on notch root surface of steel D failured at $N_{\mathrm{f}}=1.20 \times 10^{5}$ cycles. Fatigue cracks initiate mainly in matrix structure (crack A) and at matrix/second phase interface (crack B). Also, propagation of the crack is disturbed by blocky second phase (see crack A).

\section{DISCUSSION}




\section{A. Low Notch-Strength Ratio of TBF steels}

According to Majima et al., ${ }^{[16]}$ notch-strength ratio of ductile metals is mainly controlled by two primary factors, namely (i) stress triaxiality factor and (ii) a ratio of local elongation to total elongation $(L E l / T E l)$. The larger the values of the two factors, the higher the notch-strength ratio due to an increase in plastic notch-constraint. Figure 12 shows notch-strength ratios of steels A-E and F-H as a function of LEl/TEl. These notch-strength ratios tend to increase with increasing $L E l / T E L$. So, it is considered that higher notch-strength ratios of steels F-H are caused by larger LEl/TEl under a constant stress triaxiality factor.

If notch-strength ratio was plotted as a function of Vickers hardness, steels A-E exhibit lower notch-strength ratios than steels F-H (see Table II). So, the result of Figure 12 indicates that retained austenite plays a role of reducing the notch-strength ratio through the strain-induced transformation to martensite, namely through increasing uniform elongation or resultantly decreasing local elongation. In other words, it is expected that the strain-induced transformation of retained austenite relaxes effectively triaxial plastic notch-constraint in steels A-E. 
In general, notch-fatigue limit of ultrahigh-strength structural steel is saturated in a high hardness range, as shown in steels F-H (Figure 10). However, notch-fatigue limit of the present steels A-E linearly increased with Vickers hardness, even in a Vickers hardness range of HV350-450.

In the previous section, it was expected that strain-induced transformation of retained austenite relaxes effectively triaxial plastic notch-constraint in steels C-E, compared to steels F-H. In addition, fatigue crack was disturbed by blocky second phase (Figure 11). From these facts and metallurgical characteristics of steels C-E, it is considered that the followings contribute to high notch-fatigue limit or suppression of crack initiation and propagation in steels C-E.

(i) plastic relaxation of localized stress concentration due to the strain-induced transformation of a large amount of metastable retained austenite

(ii) blocky second phase due to additions of $1.0 \% \mathrm{Cr}, 0.2 \% \mathrm{Mo}$ and/or $1.5 \% \mathrm{Ni}$.

(iii) carbide-free and fine bainitic ferrite lath structure matrix without pro-eutectoid ferrite

(iv) a long-range internal stress resulting from difference in flow stress between matrix structure and blocky second phase ${ }^{[5]}$

It is expected that the (i), (iii) and (iv) mainly suppress a crack initiation and the (ii) 
mostly disturbs the crack propagation.

In the present study, retained austenite stability was nearly the same level in steels C-E (Figure 6(b)) although the carbon concentrations were different each other, because most of the retained austenite is surrounded by narrow lath-martensite. So, high volume fraction of retained austenite in steels C-E may increase further contribution of the (i).

\section{Fatigue Limits Higher than Yield Stress}

In steels A-E, maximum stresses $\left(\sigma_{\max }(F L)=F L / 0.9\right)$ corresponding to fatigue limits for smooth specimens were higher than yield stresses (Table II). According to Sugimoto et al., ${ }^{[5]}$ TBF steel is characterized by a continuous yielding and low yield stress. Also, the TBF develops a significant cyclic hardening due to mainly (i) an increase in the strain-induced transformation martensite fraction and (ii) a compressive long range internal stress in matrix structure. So, it is considered that the significant cyclic hardening and high long range internal stress resulted in smooth fatigue limits higher than yield stress in steels A-E.

It was shown in Figure 10(a) that fatigue limits of smooth specimens of steels C-E were off from a linear relation. This reason is in consideration. 


\section{CONCLUSIONS}

Notch-fatigue strength and notch-sensitivity of $0.2 \% \mathrm{C}-1.5 \% \mathrm{Si}-1.5 \% \mathrm{Mn}-0.05 \% \mathrm{Nb}$

TBF steels with different $\mathrm{Cr}$, Mo and Ni contents were investigated for an application to diesel engine common rail. Also, the notch-fatigue properties were related to the microstructure and retained austenite characteristics. The main results are summarized as follows,

(1) If $1.0 \% \mathrm{Cr}, 0.2 \% \mathrm{Mo}$ and/or $1.5 \% \mathrm{Ni}$ were added to the base steel, notch-fatigue limits of the TBF steels linearly increased with an increase in Vickers hardness, with a decrease in notch-sensitivity. In a Vickers hardness range above HV325, the notch-fatigue limits were much higher than those of SCM420, SCM435 and 440 steels.

(2) It was expected that the high notch-fatigue limits were associated with (i) carbide-free and fine bainitic ferrite lath structure matrix without pro-eutectoid ferrite, (ii) a large amount of fine metastable retained austenite and (iii) blocky martensite phase including retained austenite, which suppress a fatigue crack initiation and/or propagation.

\section{ACKNOWLEDGMENTS}


This study was supported by the Grants from Adaptable and Seamless Technology Transfer Program through Target-driven R\&D, Japan Science and Technology Agency and the Grant-in-Aid for Scientific Research (B), The Ministry of Education, Science, Sports and Culture, Japan (No.2008-20360311).

\section{REFERENCES}

1. K. Sugimoto, T. Iida, J. Sakaguchi and T. Kashima: ISIJ Int., 2000, vol. 40, pp. 902-08.

2. K. Sugimoto, J. Sakaguchi, T. Iida and T. Kashima: ISIJ Int., 2000, vol. 40, pp. 920-26.

3. K. Sugimoto, A. Kanda, R. Kikuchi, S. Hashimoto, T. Kashima and S. Ikeda: ISIJ Int., 2001, vol. 42, pp.910-15.

4. K. Sugimoto, M. Murata and S. Song: ISIJ Int., 2010, vol. 50, pp. 162-68.

5. S. Song, K. Sugimoto, S. Kandaka, A. Futamura, M. Kobayashi and S. Masuda: Mat. Sci.. Res. Int., 2003, vol. 9, pp. 223-29.

6. K. Sugimoto, J. Tsuruta and S. Song: Key Eng. Mat., 2007, vols. 345-346, pp. 247-50.

7. S. Song, K. Sugimoto, M. Kobayashi, H. Matsubara and T. Kashima: 
Tetsu-to-Hagane, 2000, vol. 86, pp. 563-69. (in Japanese)

8. T. Hojo, K. Sugimoto, Y. Mukai and S. Ikeda: ISIJ Int., 2008, vol. 48, pp. 824-29.

9. M. A. Grossman: Trans. AIME, 1942, vol. 150, pp. 226-59.

10. J. H. Hollomon and L. D. Jaffe: Trans. AIME, 1946, vol. 167, pp. 601-16.

11. H. Maruyama: J. Japan Soc. Heat Treat., 1977, vol. 17, pp. 198-204. (in Japanese)

12. D. J. Dyson, and B. Holmes: J. Iron Steel Inst., 1970, vol. 208, pp. 469-74.

13. O. Umezawa: J. Japan Inst. Light Met., 2000, vol. 50, pp. 86-93. (in Japanese)

14. J. Kobayashi, N. Yoshikawa and K. Sugimoto: to be submitted to ISIJ Int.

15. G. E. Dieter: Mechanical Metallugy (SI Metric Edition), McGraw-Hill Book Co., London, 1988, p. 403.

16. T. Majima, M. Anzai and H. Nakazawa: Trans. Japan Soc. Mech. Eng. A, 1986, vol. 52, pp. 1171-76. (in Japanese) 
Nobuo Yoshikawa et al.

Table I. Chemical composition (mass\%), martensite-start temperature $\left(M_{\mathrm{s}},{ }^{\circ} \mathrm{C}\right)$ and hardenability $\left(\Pi f_{\mathrm{i}}\right)$ of steels used. *: unmeasured.

\begin{tabular}{|c|c|c|c|c|c|c|c|c|c|c|c|c|c|c|c|}
\hline \multicolumn{2}{|c|}{ steel } & $\mathrm{C}$ & $\mathrm{Si}$ & $\mathrm{Mn}$ & $\mathrm{P}$ & S & $\mathrm{Cr}$ & Mo & $\mathrm{Ni}$ & $\mathrm{Al}$ & $\mathrm{Nb}$ & $\mathrm{O}$ & $\mathrm{N}$ & $\mathrm{M}_{\mathrm{S}}$ & $\Pi f_{i}$ \\
\hline \multirow{5}{*}{$\mathrm{TBF}$} & A & 0.20 & 1.54 & 1.53 & 0.005 & 0.0005 & - & - & - & 0.039 & 0.049 & 0.0007 & 0.0007 & 420 & 14.6 \\
\hline & $\mathrm{B}$ & 0.21 & 1.49 & 1.50 & 0.004 & 0.0019 & 0.50 & - & - & 0.040 & 0.050 & 0.0012 & 0.0012 & 407 & 30.6 \\
\hline & C & 0.20 & 1.49 & 1.50 & 0.004 & 0.0018 & 1.00 & - & - & 0.040 & 0.050 & 0.0014 & 0.0013 & 397 & 47.0 \\
\hline & $\mathrm{D}$ & 0.18 & 1.48 & 1.49 & 0.004 & 0.0029 & 1.02 & 0.20 & - & 0.043 & 0.050 & 0.0015 & 0.0010 & 407 & 76.8 \\
\hline & $\mathrm{E}$ & 0.21 & 1.49 & 1.49 & 0.003 & 0.0019 & 1.09 & 0.20 & 1.52 & 0.034 & 0.049 & 0.0009 & 0.0014 & 370 & 135 \\
\hline SCM420 & $\mathrm{F}$ & 0.21 & 0.26 & 0.86 & 0.016 & 0.018 & 1.12 & 0.16 & - & 0.035 & - & * & 0.0031 & 416 & 29.4 \\
\hline SCM435 & G & 0.35 & 0.17 & 0.78 & 0.012 & 0.019 & 1.12 & 0.16 & - & 0.033 & - & $*$ & 0.0029 & 369 & 27.4 \\
\hline SCM440 & $\mathrm{H}$ & 0.41 & 0.19 & 0.80 & $<0.005$ & 0.0009 & 1.00 & 0.20 & - & 0.044 & - & 0.0018 & 0.0009 & 351 & 26.4 \\
\hline
\end{tabular}


Nobuo Yoshikawa et al.

Table II. Metallurgical characteristics, Vickers hardness, tensile properties and fatigue properties of steels A-H.

\begin{tabular}{|c|c|c|c|c|c|c|c|c|c|c|c|c|c|c|c|c|}
\hline Steel & $\begin{array}{l}\mathrm{T}_{\mathrm{A}} \\
\mathrm{T}_{\mathrm{T}} \\
\end{array}$ & $\mathrm{f} \gamma_{0}$ & $\mathrm{C} \gamma_{0}$ & $\mathrm{f}_{\mathrm{s}}$ & $\mathrm{HV}$ & YS & TS & $\mathrm{TS}_{\mathrm{N}}$ & NSR & UEl & TEl & $\begin{array}{l}\text { LEL/ } \\
\text { TEL }\end{array}$ & FL & $\sigma_{\max }(\mathrm{FL})$ & $\mathrm{FL}_{\mathrm{N}}$ & q \\
\hline A & 400 & 9.9 & 0.98 & 1.4 & 242 & 664 & 850 & 1187 & 1.40 & 12.1 & 22.8 & 0.47 & 727 & 808 & 559 & 0.43 \\
\hline $\mathrm{B}$ & 400 & 11.2 & 0.92 & 3.0 & 313 & 821 & 1005 & 1503 & 1.50 & 13.4 & 24.0 & 0.44 & 841 & 934 & 573 & 0.67 \\
\hline $\mathrm{C}$ & 400 & 12.6 & 0.80 & 12.1 & 338 & 859 & 1202 & 1758 & 1.46 & 11.1 & 21.8 & 0.49 & 865 & 962 & 642 & 0.50 \\
\hline $\mathrm{D}$ & 400 & 13.7 & 0.69 & 12.4 & 385 & 887 & 1292 & 1931 & 1.49 & 10.2 & 21.3 & 0.52 & 884 & 982 & 705 & 0.36 \\
\hline $\mathrm{E}$ & 400 & 13.2 & 0.46 & 40.0 & 430 & 832 & 1560 & 2279 & 1.46 & 6.90 & 13.0 & 0.47 & 870 & 967 & 748 & 0.23 \\
\hline \multirow{3}{*}{$F$} & 200 & - & - & - & 472 & 1307 & 1593 & 2389 & 1.50 & 3.30 & 11.6 & 0.72 & 1090 & 1211 & 645 & 0.99 \\
\hline & 550 & - & - & - & 300 & 917 & 994 & 1542 & 1.55 & 4.50 & 16.0 & 0.72 & 778 & 864 & 563 & 0.52 \\
\hline & 600 & - & - & - & 268 & 758 & 853 & 1336 & 1.57 & 7.70 & 20.5 & 0.62 & 660 & 733 & 492 & 0.49 \\
\hline \multirow{2}{*}{ G } & 500 & - & - & - & 371 & 1112 & 1171 & 1832 & 1.56 & 4.96 & 16.1 & 0.69 & 938 & 1042 & 594 & 0.83 \\
\hline & 600 & - & - & - & 300 & 902 & 961 & 1458 & 1.52 & 6.99 & 18.2 & 0.62 & 753 & 837 & 538 & 0.57 \\
\hline \multirow{2}{*}{$\mathrm{H}$} & 450 & - & - & - & 435 & 1278 & 1414 & 2167 & 1.53 & 3.80 & 13.2 & 0.71 & 1005 & 1117 & 562 & 1.00 \\
\hline & 600 & - & - & - & 347 & 923 & 1064 & 1687 & 1.58 & 5.60 & 15.1 & 0.63 & 814 & 904 & 607 & 0.57 \\
\hline
\end{tabular}

$T_{\mathrm{A}}\left({ }^{\circ} \mathrm{C}\right)$ : austempering temperature, $T_{\mathrm{T}}\left({ }^{\circ} \mathrm{C}\right)$ : tempering temperature, $f_{\gamma 0}\left(\right.$ vol\%): volume fraction of retained austenite, $C_{\gamma 0}$ (mass\%): carbon concentration of retained austenite, $f \mathrm{~s}$ : volume fraction of second phase, HV: Vickers hardness, YS $(\mathrm{MPa})$ : yield stress or $0.2 \%$ offset proof stress, $T S(\mathrm{MPa})$ : tensile strength, $T S_{\mathrm{N}}(\mathrm{MPa})$ : notch-tensile strength, $N S R$ (=TS $\left.S_{N} / T S\right)$ : notch-strength ratio, UEl (\%): uniform elongation, TEl (\%): total elongation, LEl (\%): local elongation, FL (MPa): fatigue limit for smooth specimens, $\sigma_{\max }(\mathrm{FL})$ : maximum stress corresponding to FL (=FL/(1-0.1)), $F L_{\mathrm{N}}$ : fatigue limit for notched specimen, $q$ : notch sensitivity. 
Nobuo Yoshikawa et al.

(a)

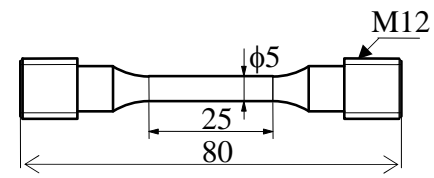

(b)

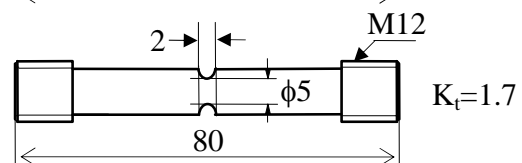

(c)

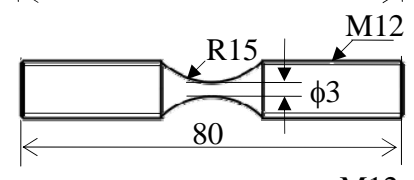

(d)

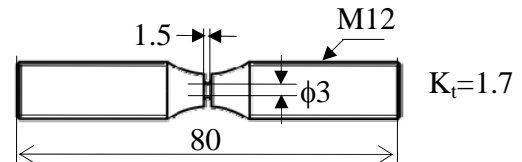

Fig. 1 - Dimensions of (a, c) smooth and (b, d) notched specimens for (a, b) tensile tests and (c, d) fatigue tests. Notch root radius of (b) and (d) is $1 \mathrm{~mm}$ and $0.75 \mathrm{~mm}$, respectively. 
Nobuo Yoshikawa et al.

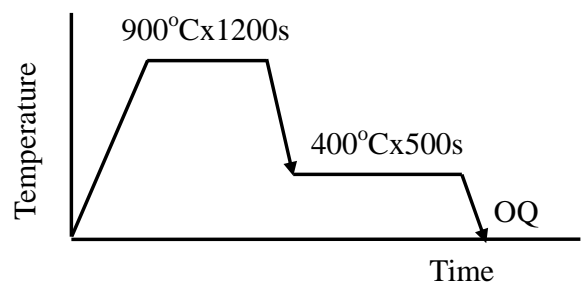

Fig. 2 - Heat treatment diagram for TBF steel. OQ represents quenching in oil. 
Nobuo Yoshikawa et al.

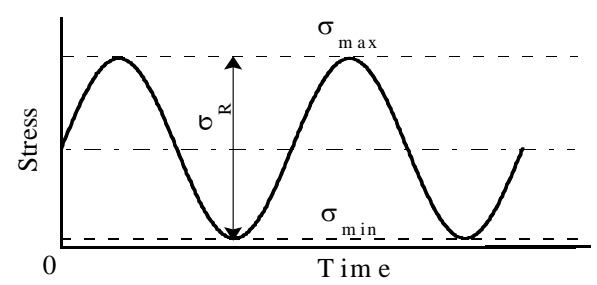

Fig. 3 - Sinusoidal curve of fatigue test. $\sigma_{\mathrm{R}}$ : stress amplitude, $\sigma_{\max }$ : maximum stress, $\sigma_{\min }$ : minimum stress. 
Nobuo Yoshikawa et al.

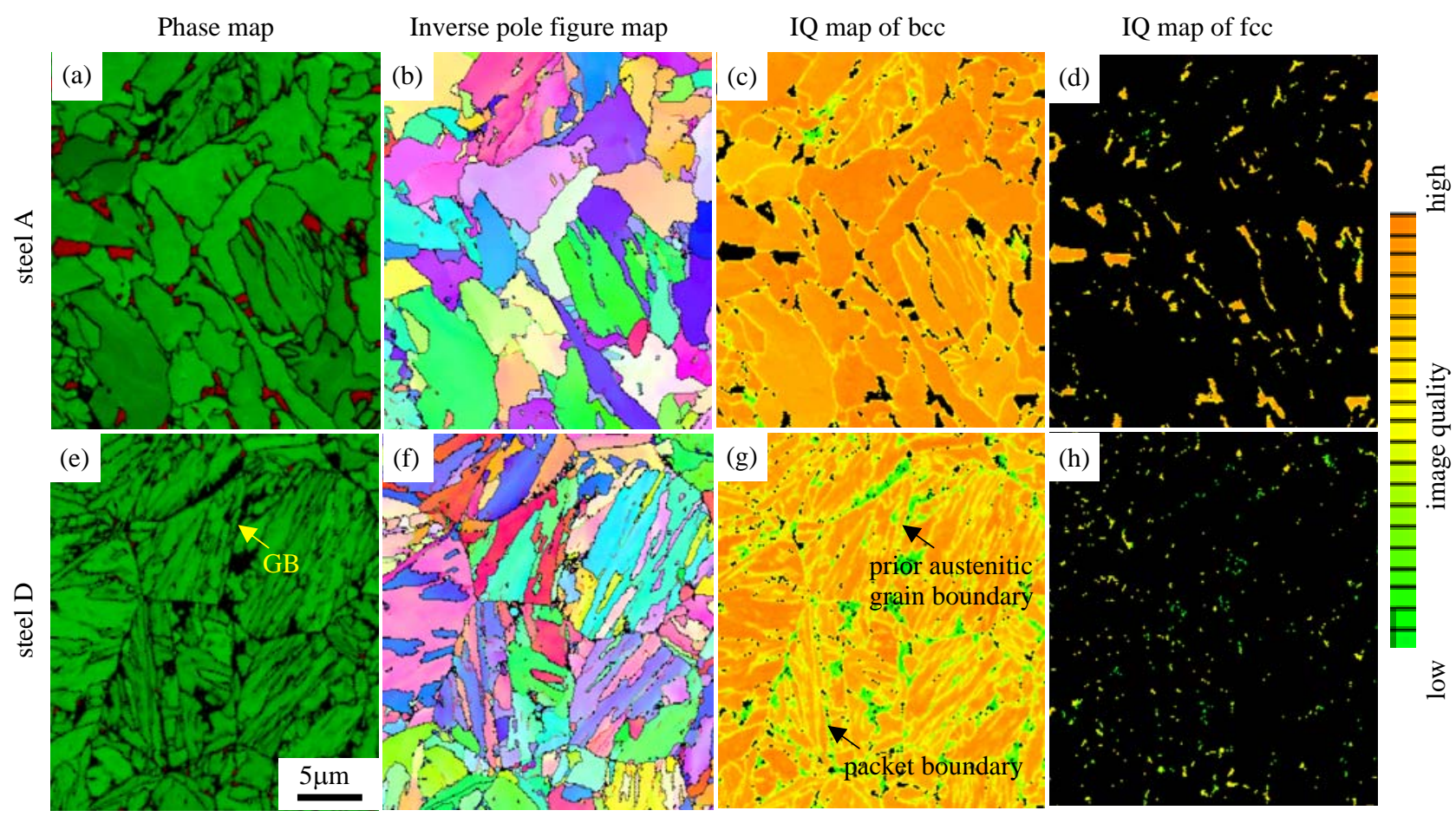

Fig. 4 - Phase maps, inverse pole figure maps and image quality (IQ) distribution maps of matrix (bcc) and retained austenite (fcc) in steels A and D. In (a) and (e), green and red phases denote matrix structure (bcc) and retained austenite (fcc), respectively. In (c) and (g), yellowish green phase is martensite. 
Nobuo Yoshikawa et al.

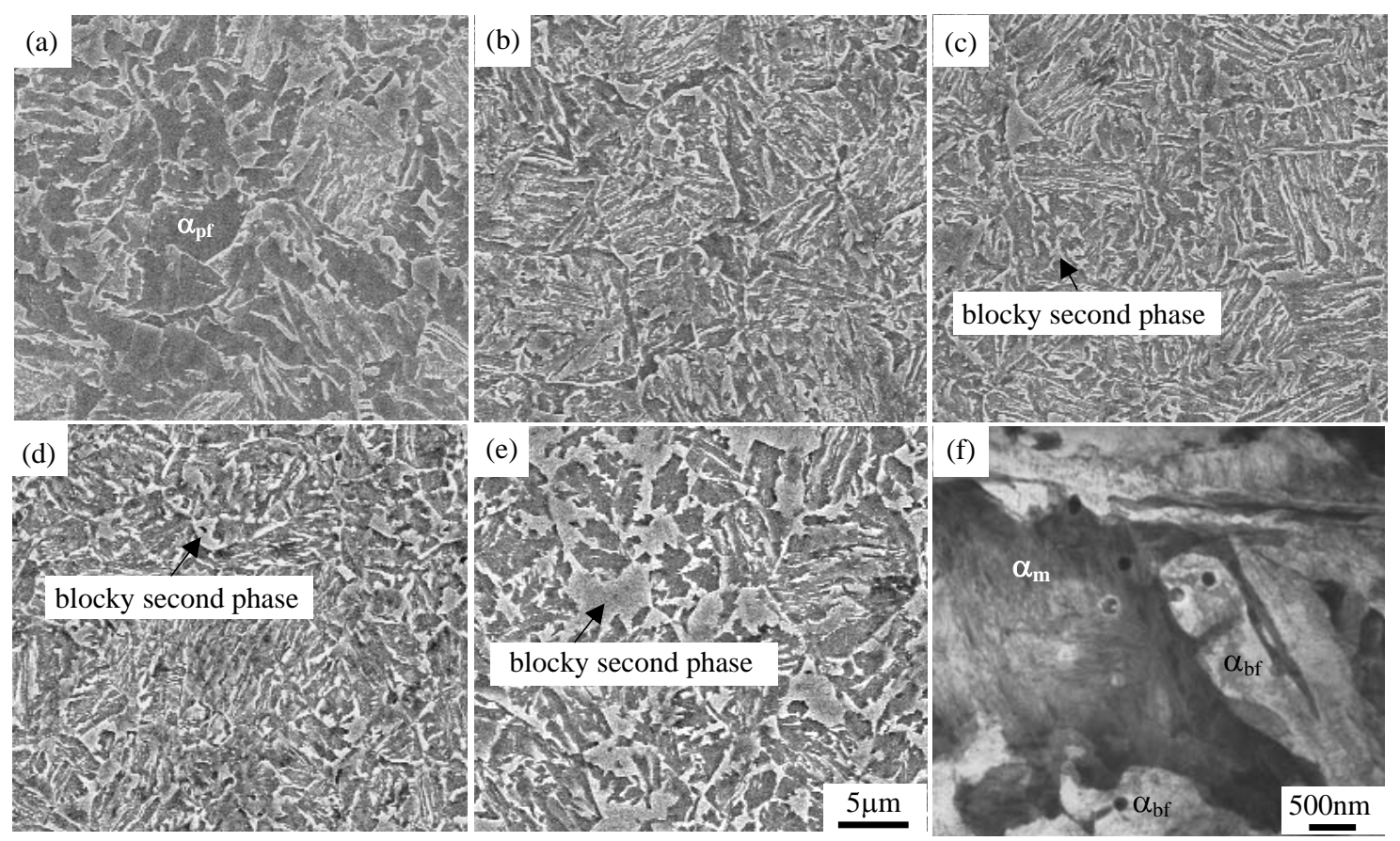

Fig. 5 - SEM images of steels (a) A, (b) B, (c) C, (d) D and (e) E and TEM image of (f) steel D in which $\alpha_{\mathrm{pf}}, \alpha_{\mathrm{bf}}$ and $\alpha_{\mathrm{m}}$ are pro-eutectoid ferrite, bainitic ferrite and martensite, respectively. 
Nobuo Yoshikawa et al.

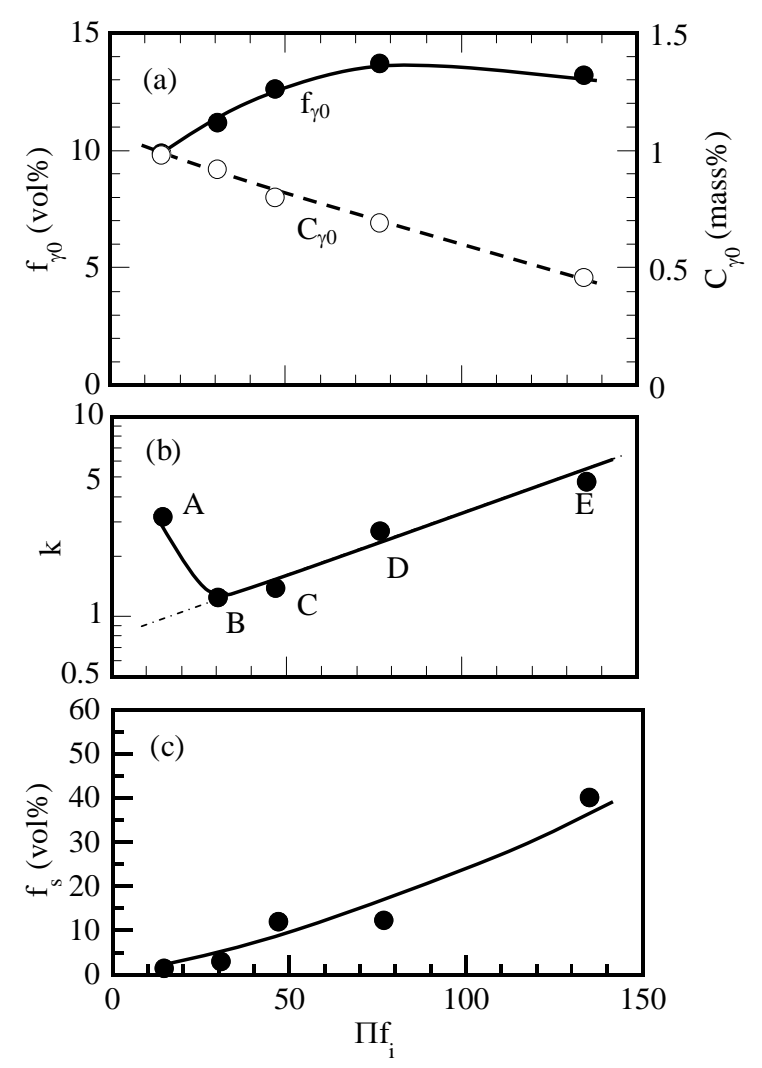

Fig. 6 - Variations in (a) initial volume fraction $\left(f_{\gamma 0}\right)$ and carbon concentration $\left(C_{\gamma 0}\right)$ of retained austenite, (b) $k$ value and (c) volume fraction of second phase $\left(f_{s}\right)$ as a function of hardenability factor $\left(\Pi f_{\mathrm{i}}\right)$ in steels A-E. 
Nobuo Yoshikawa et al.

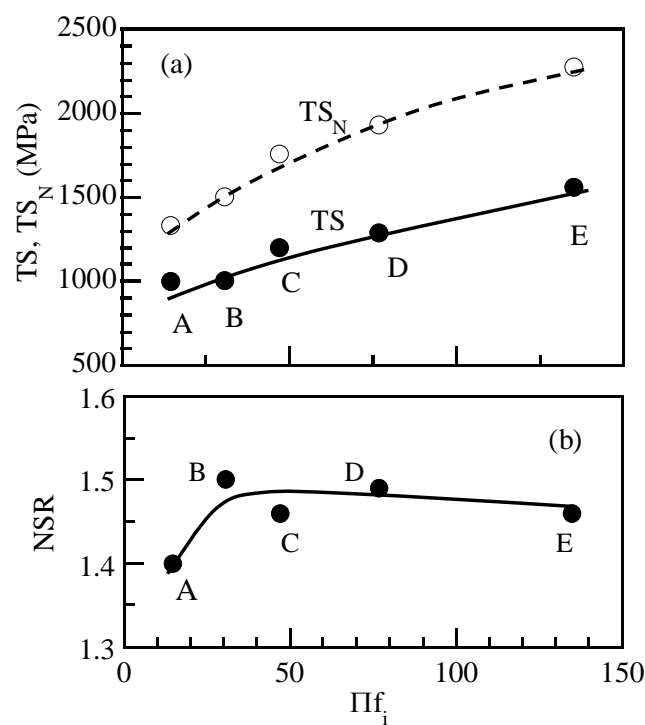

Fig. 7 - Variations in (a) tensile strength $(T S)$ and notch-tensile strength $\left(T S_{N}\right)$ and (b) notch-strength ratio $\left(N S R=T S_{N} / T S\right)$ as a function of hardenability factor in steels A-E. 
Nobuo Yoshikawa et al.
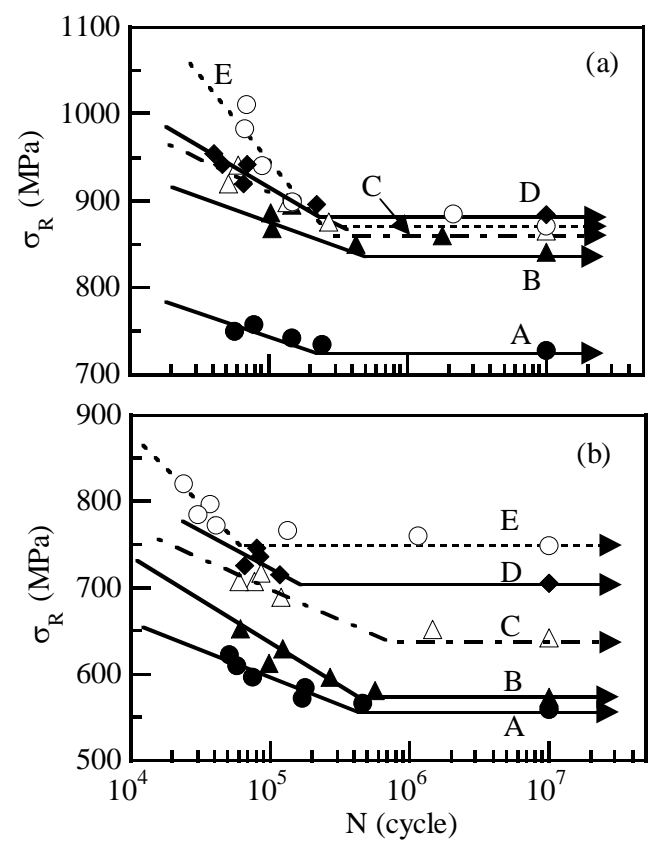

Fig. 8 - Stress amplitude $\left(\sigma_{\mathrm{R}}=\sigma_{\max }-\sigma_{\min }\right)$ - number of cycles $(N)$ curves of (a) smooth and (b) notched specimens in steels A-E. 
Nobuo Yoshikawa et al.

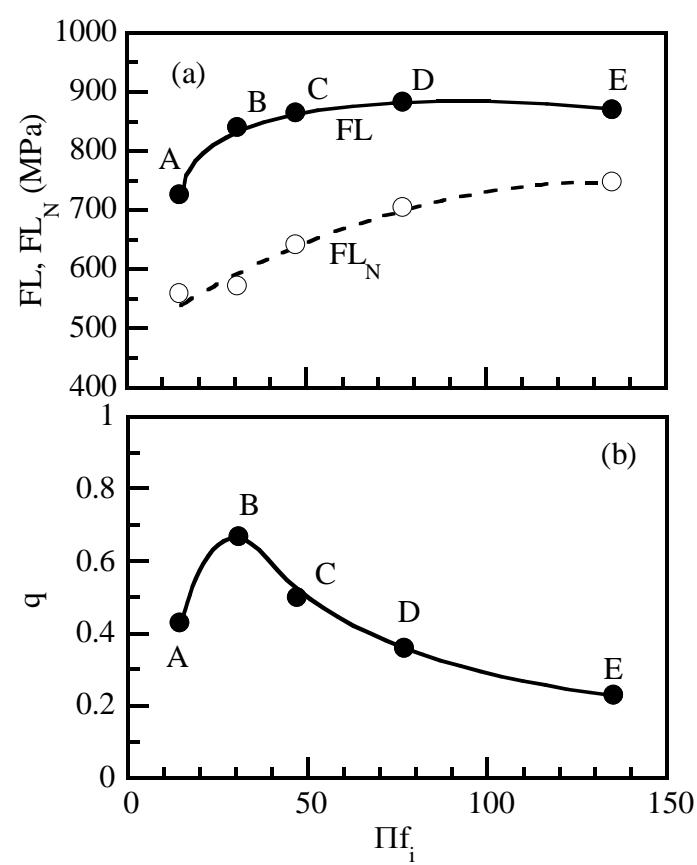

Fig. 9 - Variations in (a) fatigue limits $\left(F L, F L_{N}\right)$ of smooth and notched specimens and (b) notch-sensitivity factor $(q)$ as a function of hardenability factor $\left(\Pi f_{\mathrm{i}}\right)$ in steels A-E. 
Nobuo Yoshikawa et al.

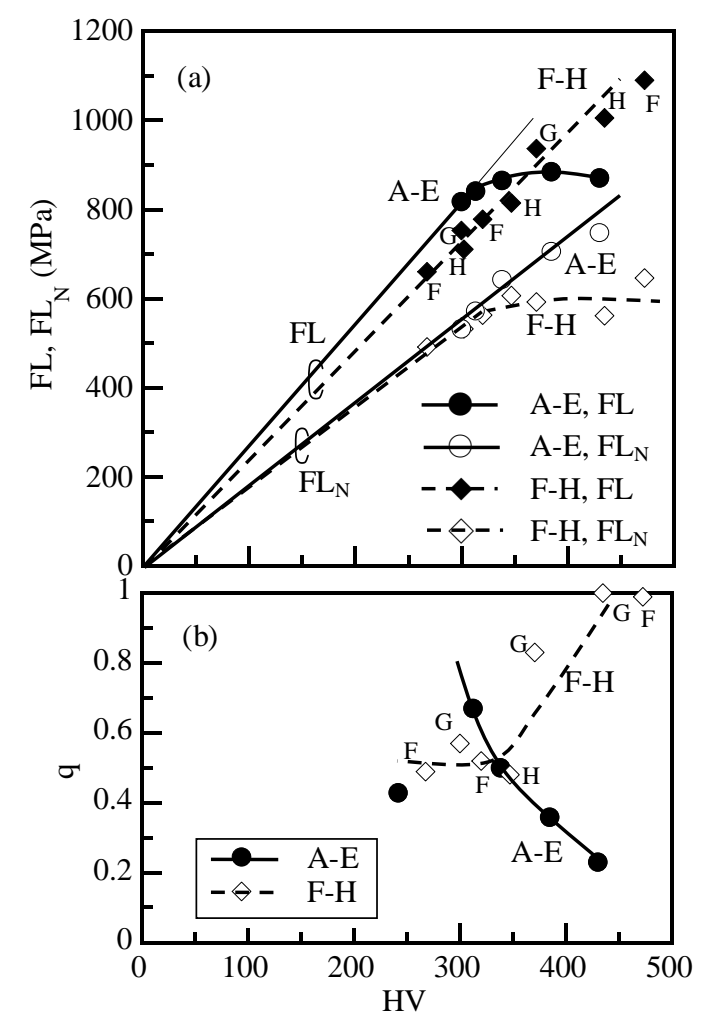

Fig. 10 - Variations in fatigue limits $\left(F L, F L_{\mathrm{N}}\right)$ of smooth and notched specimens and (b) notch-sensitivity $(q)$ as a function of Vickers hardness $(H V)$ in steels A-E and F-H. 
Nobuo Yoshikawa et al.

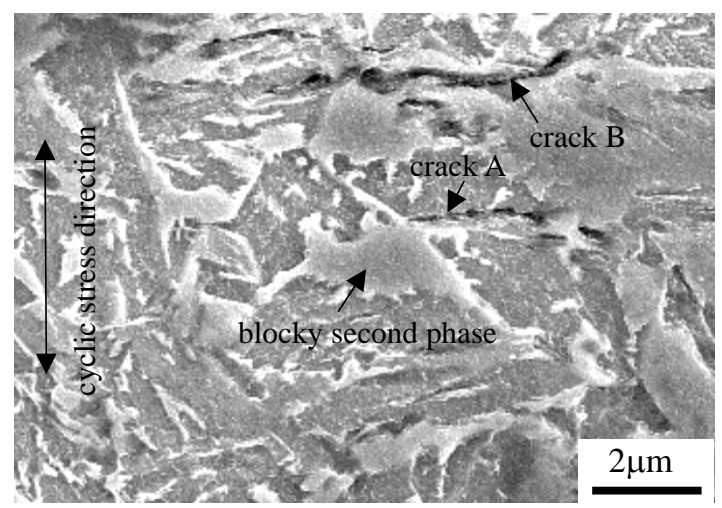

Fig. 11 - Typical SEM image of fatigue cracks initiating on notched root surface of steel D $\left(N_{\mathrm{f}}=1.10 \times 10^{5}\right.$ cycles $)$. 
Nobuo Yoshikawa et al.

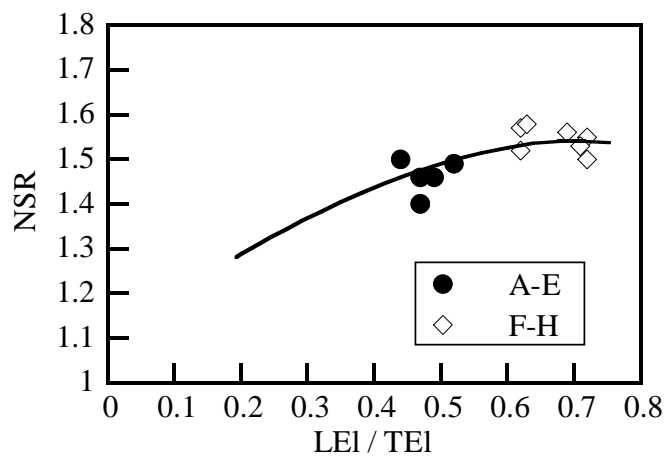

Fig. 12 - Relationship between notch-strength ratio $\left(N S R=T S_{N} / T S\right)$ and $L E l / T E L$ in steels A-E and F-H. 